\title{
STATUS PEMANFAATAN IKAN CAKALANG (Katsuwonus pelamis)) DI PERAIRAN KABUPATEN LUWU SULAWESI SELATAN
}

\author{
(Status of Utilization of Skipjack Tuna (Katsuwonus Pelamis) \\ in the Luwu Waters, South Sulawesi) \\ Muhammad Jamal ${ }^{1)}$, Hasrun ${ }^{1)}$, Ernaningsih ${ }^{1)}$ \\ 1) Program Studi Pemanfaatan Sumberdaya Perikanan FPIK UMI Makassar
}

Korespondensi: muhammadjamalalwi@umi.ac.id

Diterima: 10 Agustus 2019; disetujui 22 Oktober 2019

\begin{abstract}
Skipiack tuna (Katsuwonus pelamis). should be managed properly because even though it is renewable, natural resources can be depleted. One approach in managing fish resources is by modeling. The purpose of this study is to determine the maximum sustainable vield, the level of utilization and effort of skipiack tuna. Data on catches as well as catch efforts of skipiack tuna were collected from 9 fisheries year books of Luwu Kabupaten (District). The surplus production model used is the Schaefer, Fox. Walter \& Hilborn model. Schaefer model obtained by MSY $=1541.08$ tons and Fopt $=243$ trips; Fox model obtained maximum sustainable vield value ( $\left.\mathrm{Y}_{\mathrm{MSY}}\right)$ of 1602,244 tons, maximum sustainable fishing effort ( $f_{\mathrm{MSY}}$ ) of 303 units and maximum sustainable CpUE value ( $\mathrm{U}_{\mathrm{MSY}}$ ) of 5.29 tons trip ${ }^{-1}$ : the Walter \& Hilborn model found potential stocks of sustainable reserves (Be) skipiack in Luwu district amounted to 935.72 tons year $^{-1}$. Utilization rates of the skpjack tuina indicate the fish is still under exploitation.
\end{abstract}

Keywords : Surplus Production Model, Skipjack Tuna, Sustainable maximum, Catch, Luwu.

\begin{abstract}
ABSTRAK
Ikan Cakalang (Katsuwonus pelamis), seyogyanya dikelola dengan baik karena walaupun sebagai sumberdaya alam terbarukan dapat saja mengalami deplesi. Salah satu pendekatan dalam pengelolaan sumberdaya ikan ialah dengan pemodelan. Tujuan penelitian adalah mengetahui tangkapan maksimum lestari, tingkat pemanfaatan dan pengupayaan ikan cakalang. Data hasil tangkapan dan upaya tangkap ikan cakalang dikumpulkan dari laporan tahunan perikanan selama 9 tahun dari Dinas Kelautan dan Perikanan Kabupaten Luwu. Model produksi surplus yang digunakan adalah model Schaefer, Fox, Walter\&Hilborn. Model schaefer dipeoleh MSY $=1541,08$ ton dan Fopt $=243$ trip ; model Fox diperoleh nilai hasil tangkapan maksimum lestari ( $\mathrm{Y}_{\mathrm{MSY}}$ ) sebesar 1602,244 ton, upaya penangkapan maksimum lestari ( $f_{\text {MSY }}$ ) sebesar 303 unit dan nilai CpUE maksimum lestari (U $\mathrm{U}_{\mathrm{MSY}}$ ) sebesar 5,29 ton/trip ; model Walter \& Hilborn didapatkan potensi stok cadangan lestari $\left(B_{e}\right)$ ikan cakalang di kabupaten luwu sebesar 935,72ton/tahun. Tingkat pemanfaatan ikan cakalang menunjukkan eksploitasi ikan ini masih tergolong rendah.
\end{abstract}

Kata Kunci : Model Produksi Surplus, Ikan cakalang, Tangkapan Maksimum lestari, Luwus. 


\section{PENDAHULUAN}

$\begin{array}{lcr}\text { Ikan } & \text { cakalang } & \text { (Katsuwonus } \\ \text { pelamis) } & \text { tergolong } & \text { sumberdaya } \\ \text { perikanan } & \text { pelagis besar yang penting } \\ \text { dan merupakan salah satu komoditi }\end{array}$
ekspor nonmigas. Potensi ikan cakalang di Teluk Bone mencapai sekitar $\quad 61.800$ ton per tahun. Penelitian tentang ikan cakalang umumnya membahas tentang eksploitasi untuk meningkatkan produksi, belum banyak yang meneliti tentang status pemanfaatan (termasuk aspek kelestarian dan efisiensi).

Penangkapan ikan cakalang di perairan Kabupaten Luwu telah berlangsung cukup lama dengan intensitas yang padat. Data mengenai tingkat pemanfaatan sumberdaya ikan sangat penting, karena akan menentukan apakah pemanfaatan sumberdaya tersebut kurang optimal, optimal, atau berlebih. Pemanfaatan sumberdaya ikan yang berlebihan akan mengancam kelestariannya. Dengan mengetahui tingkat pemanfaatan sumberdaya ikan cakalang, diharapkan dapat dilakukan pengelolaan yang berkelanjutan.

Penelitian ini bertujuan untuk mengetahui berapa besar hasil tangkapan maksimum lestari
(Maximum Sustainable Yield = $M S Y$ ), tingkat pemanfaatan, dan tingkat pengupayaan ikan cakalang di perairan Kabupaten Luwu.

\section{METODE PENELITIAN}

Penelitian telah dilaksanakan dari selama 6 bulan dari bulan April sampai Oktober 2018 di Kabupaten Luwu Sulawesi Selatan. Data yang dikumpulkan adalah data produksi hasil tangkapan ikan cakalang yang tertangkap dengan alat tangkap pole and line. Data ini berupa data sekunder yang diperoleh dari Dinas Kelautan dan Perikanan Kabupaten Luwu selama periode 2005 - 2013. Surplus Produksi adalah model yang paling sederhana dalam dinamika populasi ikan ialah model produksi surplus yang memperlakukan populasi ikan sebagai biomassa tunggal yang tidak dapat dibagi, yang tunduk pada aturanaturan sederhana dari kenaikan dan penurunannya. Model produksi ini tergantung pada 4 macam besaran, yaitu : biomassa populasi pada suatu waktu tertentu $\mathrm{t}(\mathrm{Bt})$, tangkapan untuk suatu waktu tertentu $\mathrm{t}(\mathrm{Ct})$, upaya tangkap pada waktu tertentu $\mathrm{t}(\mathrm{Et})$, dan laju pertumbuhan alami konstan (r). Model ini pertama kali dikembangkan oleh 
Schaefer, yang bentuk awalnya sama dengan model pertumbuhan logistik.

Menurut Coppola dan Pascoe (1996), persamaan surplus produksi terdiri dari beberapa konstanta yang dipengaruhi oleh pertumbuhan alami, kemampuan alat tangkap, dan daya dukung lingkungan. Konstantakonstanta tersebut diduga dengan menggunakan model-model penduga parameter biologi dari persamaan surplus produksi, yaitu model: Equilibrium Schaefer, Disequilibrium Schaefer dan Walter- Hilborn. Berdasarkan ketiga model tersebut dipilih yang paling sesuai atau best fit dari pendugaan yang lain.

Menurut Sparre dan Venema (1999), rumus-rumus model produksi surplus hanya berlaku apabila parameter slope (b) bernilai negatif, yang berarti penambahan upaya tangkap akan menyebabkan penurunan hasil tangkapan per upaya tangkap. Apabila parameter $b$ nilainya positip, maka tidak dapat dilakukan pendugaan besarnya stok maupun upaya optimum, tetapi hanya dapat disimpulkan bahwa penambahan upaya tangkap masih memungkinkan untuk meningkatkan hasil tangkapan.
Pendugaan upaya penangkapan optimum (Eopt) dan hasil tangkapan maksimum lestari (CMSY) didekati dengan Model Produksi Surplus. Antara hasil tangkapan per satuan upaya (Catch Per Unit of Effort = CPUE) dan upaya tangkap (effort) dapat berupa hubungan linear maupun eksponensial (Gulland, 1983). Model Produksi Surplus terdiri dari 2 model dasar yaitu Model Schaefer (hubungan linear) dan Model Gompertz yang dikembangkan oleh Fox dengan bentuk hubungan eksponensial (Gulland, 1983).

Model Produksi Surplus pertama kali dikembangkan oleh Schaefer, yang bentuk awalnya sama dengan model pertumbuhan logistik. Model tersebut ialah sebagai berikut:

$$
\mathrm{CpUE}=\mathrm{a}+\mathrm{bf}
$$

Hubungan antara effort (f) dengan catch (C) maka:

$$
\mathrm{C}=\mathrm{af}-\mathrm{bf^{2 }}
$$

kemudian effort optimum (fopt) dapat diperoleh dengan menyamakan turunan pertama catch terhadap effort $=0$, sehingga

$$
\begin{gathered}
C=a f-b f^{2} \\
C=a-2 b f=0
\end{gathered}
$$




$$
\text { Fopt }=-\frac{\mathbf{a}}{2 \mathbf{b}}
$$

Untuk mendapatkan nilai maksimum lestari adalah sebagai berikut :

$$
\begin{gathered}
\operatorname{MSY}=a(a / 2 b)-b\left(a^{2} / 4 b^{2}\right) \\
M S Y=-\frac{a^{2}}{4 b}
\end{gathered}
$$

di mana :

$\mathrm{a}=$ Intersep (titik perpotongan garis regresi dengan sumbu y)

$\mathrm{b}=$ Slope (kemiringan garis regresi)

Fox menyatakan bahwa hubungan antara effort $(\mathrm{ft})$ dan catch $\left(\mathrm{C}_{\mathrm{t}}\right)$ adalah bentuk eksponensial dengan kurva yang tidak simetris, dan dinyatakan bahwa hubungan antara effort ( $\mathrm{ft}_{\mathrm{t}}$ dan catch per unit effort (CPUEt) adalah sebagai berikut:

$$
\operatorname{CPUE}_{\mathrm{t}}=\frac{\mathrm{c}_{\mathrm{t}}}{\mathrm{f}_{\mathrm{t}}}=\mathrm{e}^{\left(\mathrm{a}+\mathrm{b} \mathrm{f}_{\mathrm{t}}\right)}
$$

hubungan antar effort dan catch adalah:

$$
C_{\tau}=f_{t} e^{\left(a+b f_{t}\right)}
$$

Upaya optimum (fopt) diperoleh dengan cara menyamakan turunan pertama

catch $\left(\mathrm{C}_{\mathrm{t}}\right)$ trhadap effort ( $\left.\mathrm{ft}\right)$ sama dengan nol:

sehingga:

$$
\begin{aligned}
& \frac{d c_{t}}{d f_{t}}=e^{\left(a+b f_{t}\right)}+f_{t} e^{\left(a+b f_{t}\right)}(b)=0 \\
& f_{\text {opt }}=-\frac{1}{b}
\end{aligned}
$$

Produksi maksimum lestari (MSY) diperoleh dengan mnsubsitusikan nilai upaya optimum ke dalam persamaan sehingga:

$$
C_{\max }=M S Y=-\frac{1}{b} e^{a-1}
$$

besarnya parameter a dan $b$ secara sistematis dapat dicari dengan mempergunakan persamaan regresi. Rumus-rumus untuk model produksi surplus ini hanya berlaku bila parameter slope (b) bernilai negatif, artinya penambahan jumlah effort akan menyebaban penurunan CPUE.

$$
\text { Walter \& }
$$

Hilborn mengembangkan jenis lain dari model produksi surplus, yang dikenal dengan sebagai model regresi. Perbedaan antara Model Walter dan hilborn dengan Model Schaefer adalah Model Walter dan Hilborn dapat memberikan dugaan masing-masing untuk parameter fungsi produksi surplus $\mathrm{r}$, q, dan $\mathrm{K}$.

$$
\begin{gathered}
P_{(t+1)}=P_{t}+\left[r * P_{t}-\left(\frac{r}{k}\right) * P_{t}^{2}\right] \\
-q * e_{t} * P_{t}
\end{gathered}
$$

Dimana :

$P_{(t+1)}=$ Besarnya stok biomassa pada waktu $\mathrm{t}+1$

$P_{t} \quad=$ Besarnya stok biomassa pada waktu $\mathrm{t}$

$\mathrm{r} \quad=$ Laju pertumbuhan instrinsik stok biomassa (konstan) $\mathrm{k}=$ Daya dukung maksimum lingkungan alami 


$$
\begin{aligned}
\mathrm{q}= & \text { Koefisien penangkapan } \\
e_{t}= & \text { Jumlah upaya penangkapan } \\
& \text { untuk mengeksploitasi } \\
& \text { biomas tahun } \mathrm{t} \text { (trip/alat } \\
& \text { tangkap) }
\end{aligned}
$$

Untuk jumlah hasil tangkapan (cacth, C), upaya penangkapan (trip/alat tangkap, e), hasil tangkapan per trip alat tangkap, upaya penangkapan (CPUE), dan potensi lestari $(\mathrm{Pe})$ pada kondisi keseimbangan diduga dengan menggunakan persamaan berikut :

$$
\begin{gathered}
C_{M S Y}=\frac{1}{4} * r * \mathrm{k} \\
e_{\text {opt }}=\frac{r}{2 * q} \\
P_{e}=\frac{k}{2} \\
U_{e}=\frac{q * k}{2}
\end{gathered}
$$

Tingkat pemanfaatan sumberdaya ikan cakalang dapat diketahui setelah didapatkan $\mathrm{C}_{\mathrm{MSY}}$. Kemudian dihitung dengan cara mempersenkan jumlah hasil tangkapan pada tahun tertentu terhadap JTB (Jumlah Tangkapan yang dibolehkan). Menurut Dahuri, R. (2010), JTB tersebut adalah $80 \%$ dari potensi maksimum lestari ( $\left.\mathrm{C}_{\mathrm{MSY}}\right)$.

\section{HASIL DAN PEMBAHASAN}

Berdasarkan Data Statistik Perikanan Kabupaten Luwu Sulawesi Selatan tahun 2005 - 2013, alat tangkap yang dioperasikan di Perairan kabupaten luwu menangkap ikan cakalang adalah pole and line (Tabel 1).

Tabel 1. Hubungan antara produksi hasil tangkapan (ton) terhadap Jumlah Upaya (trip) pole and line Periode Tahun 2005 - 2013

\begin{tabular}{cccc}
\hline Tahun & $\begin{array}{c}\text { Produksi Hasil } \\
\text { Tangkapan (Ton) }\end{array}$ & $\begin{array}{c}\text { Jumlah Upaya (trip) } \\
\text { pole and line }\end{array}$ & CPUE \\
\hline 2005 & 1311.3 & 160 & 8,20 \\
2006 & 1330.8 & 155 & 8,59 \\
2007 & 1250 & 135 & 9,26 \\
2008 & 1325.6 & 145 & 9,14 \\
2009 & 1311.6 & 160 & 8,20 \\
2010 & 1429.6 & 180 & 7,94 \\
2011 & 1501.1 & 180 & 8,34 \\
2012 & 1520.5 & 220 & 6,91 \\
2013 & 1538.6 & 226 & 6,81 \\
\hline
\end{tabular}

Jumlah upaya penangkapan sedangkan paling sedikit terjadi pada terbanyak yang dioperasikan terjadi tahun 2007 sebanyak 135 trip. Jumlah pada tahun 2013 sebanyak 226 trip produksi hasil tangkapan ikan cakalang 
terbanyak terjadi pada tahun 2013 sebanyak 1538,6 ton dan jumlah hasil tangkapan ikan cakalang paling sedikit terjadi pada tahun 2007 sebanyak 1250 ton, hal ini terjadi karena pada tahun tersebut mengalami kenaikan hasil tangkapan yang cukup tinggi, kemungkinan disebabkan terjadinya penambahan jumlah alat tangkap pole and line atau kenaikan jumlah trip alat tangkap yang menghasilkan keuntungan tinggi.

Nelayan yang menangkap ikan cakalang di daerah penelitian merupakan nelayan tradisional yang hanya mengandalkan pengalaman dalam melakukan operasi penangkapan (trial fishing). Menurut Charles (2001) bahwa aktivitas penangkapan ikan cakalang di perairan pedalaman sering didominasi oleh usaha perikanan komersial skala kecil dan perikanan subsisten yang bekerja musiman dan untuk konsumsi yang salah satu ciricirinyanya ialah nelayan melakukan penangkapan hanya dengan mengandalkan pengalaman.

Seiring dengan pengalaman nelayan dalam melakukan penangkapan ikan cakalang maka hasil yang diperoleh nelayan terus meningkat dari tahun ke tahun berikutnya. Sparre dan
Venema (1999), menjelaskan bahwa beberapa asumsi yang di gunakan dalam pendugaan stok suatu sumberdaya perairan adalah stok sumberdaya ikan cakalang menyebar merata di daerah tersebut, seluruh data hasil tangkapan sumberdaya yang diperoleh berasal dari daerah tersebut, seluruh hasil tangkapan di daratkan didaerah tersebut dan tidak ada perubahan signifikan dalam tingkat teknologi penangkapan ikan selama kurun waktu pengambilan data.

Pendugaan besarnya suatu stok perlu dilakukan secara kuantitatif yaitu karena yang pertama menentukan status dan produktivitas sumberdaya dan yang kedua adalah untuk mengevaluasi konsekuensi dari tindakan manajemen alternatif, sehingga pada sumbedaya perikanan ikan cakalang saat pertumbuhan turun diikuti oleh biomass sedangkan hasil tangkapan naik. Hal ini akan berpengaruh terhadap kondisi ikan cakalang selanjutnya.

Untuk melihat pengaruh upaya penangkapan (f) dengan hasil tangkapan per trip upaya (CPUE) digunakan analisis regresi linier sederhana (Sparre dan Venema, 1999). Selanjutnya dikaatakan bahwa penggunaan persamaan linier sederhana 
untuk mengetahui besarnya pengaruh antar peubah dan juga mengetahui nilai satu atau lebih peubah.

Hasil analisis pengaruh upaya pengkapan (f) terhadap hasil tangkapan perunit upaya (CPUE) ikan cakalang dengan menggunakan analisis regresi model surplus produksi Schaefer diperoleh nilai $\mathrm{a}=12,67, \mathrm{~b}=-0,0260$, nilai $\mathrm{R}^{2}=0,93$ dengan simpangan baku $=0,237$. Persamaan regresi yang dihasilkan antara hasil tangkapan ikan cakalang (ton) dengan upaya penangkapan (effort) adalah $\mathrm{Y}=12,67 \mathrm{f}$ - (-0,0260) $\mathrm{f}^{2}$, sedangkan persamaan regresi yang dihasilkan antara hasil tangkapan ikan cakalang per upaya penangkapan dengan upaya penangkapan (effort) ialah $\mathrm{Y} / \mathrm{f}=\mathrm{U}=$ 12,67 - (-0,0260) f. Hubungan antara upaya penangkapan (f) dengan hasil tangkapan per trip upaya (CPUE) berdasarkan hasil analisis diperoleh hubungan yang kuat. Hal ini didasarkan pada nilai koefisien korelasi (multiple R) yakni $=0,96$ yang berarti bahwa koerelasi upaya pengkapan (f) terhadap CPUE $(U)=0,96$ dengan nilai $\mathrm{R}^{2} 0,93$ memiliki pengertian bahwa variasi CPUE dapat dipengaruhi oleh variasi upaya penangkapan $=93$ persen. Nilai simpangan baku $(\mathrm{Sb})=0.23$ artinya bahwa kecilnya penyimpangan koefisien regresi variabel upaya penangkapan telah memberikan kontribusi yang signifikan terhadap variabel CPUE. Variabel bebas (upaya penangkapan) secara simultan mampu menjelaskan perubahan pada variabel tergantung (CPUE), hal ini ditunjukkan dengan nilai significance $F$ sebesar 0,000024 (jika nilai $F$ hitung sebesar 96,58) .

Hasil analisis potensi lestari ikan cakalang dengan menggunakan model surplus produksi Schaefer. memperlihatkan model ini tidak realistis digunakan untuk mengestimasi nilai tangkapan maksimum lestari (YMSY) dari ikan cakalang, upaya penangkapan maksimum lestari (f $\mathrm{f}_{\mathrm{MSY}}$ ) dan nilai CPUE maksimum lestari (UMSY). Hal ini diakibatkan tingkat upaya (effort) yang sangat tinggi yaitu terjadi pada setiap tahunnya, sedangkan nilai -a/b (dimana a ialah intercept dan b adalah slope) $=243$. sedangkan asumsi realistis dalam model Schaefer ialah nilai $-\mathrm{a} / \mathrm{b}$ adalah bernilai positif dan nilai CPUE (U) adalah nol untuk nilai $f=-a / b$, sehingga nilai negatif dari hasil tangkapan perunit upaya (CPUE) adalah realistis, maka model Schaefer hanya dapat diterapkan terhadap nilai- 
nilai f (effort) yang lebih rendah dari nilai $-\mathrm{a} / \mathrm{b}$ atau nilai effort harus tidak boleh melebihi nilai $-\mathrm{a} / \mathrm{b}$. Kenyataan yang diperoleh ialah tingkat upaya (effort) setiap tahunnya belum melewati asumsi realistis tersebut yakni nilai effort belum melebihi $-\mathrm{a} / \mathrm{b}$ sehingga menyababkan nilai estimasi hasil tangkapan menjadi relistis (bernilai negatif, dan estimasi hasil tangkapan perunit upaya juga menjadi realistis (bernilai negatif).

Berdasarkan penjelasan diatas menunjukkan bahwa model Schaefer menjadi sangat realistis untuk digunakan dalam mengestimasi hasil tangkapan maksimum lestari ( $\mathrm{Y}_{\mathrm{MSY}}$ ), upaya penangkapan maksimum lestari (fMSY) dan nilai CPUE maksimum lestari (UMSY) ikan cakalang di lokasi penelitian dan model ini yang disarankan selain dengan menggunakan model Fox. Menurut Trevor dan Julia
(2012), menjelaskan bahwa konsep ini telah banyak diterapkan oleh lembagalembaga pengelolaan perikanan di dunia dengan tujuan keberlanjutan sumberdaya.

Pengaruh upaya penangkapan (f) terhadap hasil tangkapan perunit upaya (CpUE) ikan cakalang dengan menggunakan analisis regresi model Fox diperoleh nilai a sebesar 2,666, b sebesar -0,0033, nilai $\mathrm{R}^{2}$ sebesar 0,94 dan simpangan baku sebesar 0,02. Persamaan regresi yang dihasilkan antara hasil tangkapan ikan cakalang (Ton) dengan upaya penangkapan (effort) ialah $\mathrm{Y}=\mathrm{f} * \mathrm{e}^{(\mathbf{0 , 2 6 6 6 - ( - 0 , 0 0 3 3} * \mathrm{f})}$ (Gambar 1), sedangkan persamaan regresi yang dihasilkan antara hasil tangkapan ikan cakalang per upaya penangkapan dengan upaya penangkapan (effort) ialah $\mathrm{U}=\mathrm{e}^{\mathbf{( 6 , 5 0 8}-}$ $\mathbf{0 , 0 0 0 4 8 5 * f )}$ (Gambar 2).

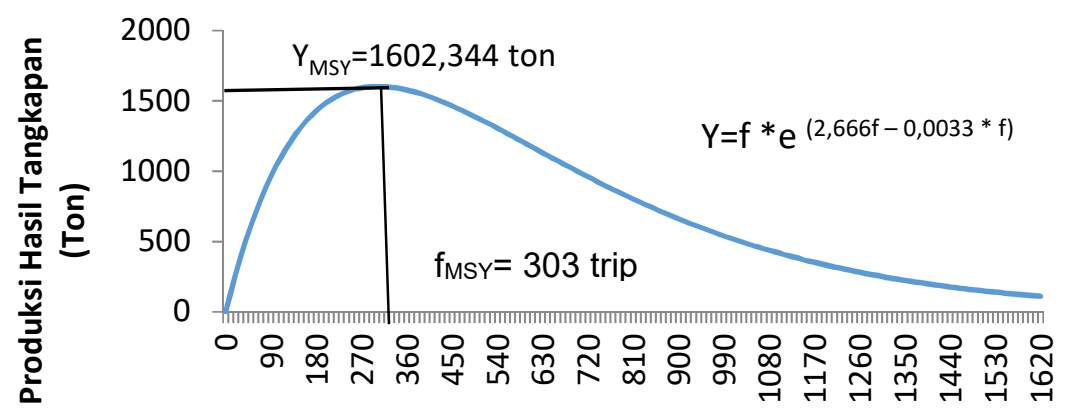

Jumlah Upaya (trip)

Gambar 1. Kurva Hubungan Cacth-Effort Model Fox 


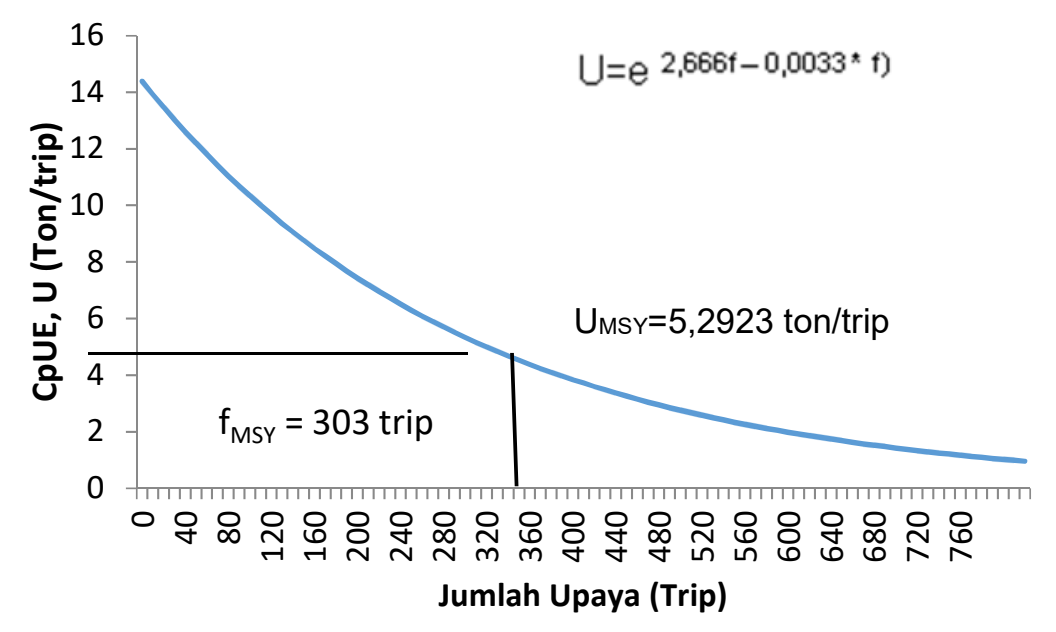

Gamar 2. Kurva Hubungan CpUE - Effort Model Fox

Hasil analisis potensi lestari ikan cakalang dengan model Fox, maka diperoleh nilai hasil tangkapan maksimum lestari ( $\mathrm{Y}_{\mathrm{MSY}}$ ) ikan cakalang sebesar 1602,244 ton, upaya penangkapan maksimum lestari ( $f_{\mathrm{MSY}}$ ) sebesar 303 unit dan nilai CPUE maksimum lestari ( $\mathrm{U}_{\mathrm{MSY}}$ ) sebesar 5,29 ton/trip.

Kriteria status pemanfaatan sumbardaya perikanan yang dikembangkan FAO (1995) dan Bintoro (2005), maka kriteria status perikanan ikan cakalang kabupaten luwu berdasarkan model Fox pada tahun 2014 tergolong underexploited yaitu stok sumberdaya ikan cakalang telah tereksploitasi belum melebihi nilai MSY (maximum sustainable yield). Hal tersebut disebabkan produksi pada tahun 2013 sebesar 1538,60 ton yang berarti stok sumberdaya ikan cakalang yang tereksploitasi belum melebihi nilai MSY sebesar 1602,344 ton. Sedangkan upaya penangkapan pada tahun 2013 sebesar 226 unit penangkapan belum melebihi upaya penangkapan maksimum lestari ( $f_{\mathrm{MSY}}$ ) sebesar 303 unit yakni belum melebihi sebesar 93 \%. Berdasarkan hal ini, maka jumlah upaya penangkapan harus ditingkatkan sebesar 77 unit untuk mencapai nilai maksimum sustainable yield di kabupaten luwu sulawesi selatan.

Tingkat Pemanfaatan (TP) ikan cakalang selama 9 tahun terakhir belum melebihi tingkat pemanfaatan yang diperbolehkan (JTB) yakni dalam kondisi underexploited. Tingkat Pemanfaatan (TP) ikan cakalang pada setiap tahunnya belum melebihi $195 \%$ dari JTB, sedangkan Tingkat 
Pengupayaan $\left(\mathrm{TP}_{\mathrm{U}}\right)$ alat tangkap untuk pengeksploitasi ikan cakalang di lokasi penelitian, diperoleh hasil analisis bahwa Tingkat Pengupayaan $\left(\mathrm{TP}_{\mathrm{U}}\right)$ selama 9 tahun terakhir belum melebihi tingkat upaya maksimum lestari (f Jтв $)$ ikan cakalang (Tabel 2)

Tabel 2. Tingkat Pemanfaatan (TP) dan Tingkat Pengupayaan (TPu) ikan cakalang di kabupaten luwu Sulawesi Selatan.

\begin{tabular}{cccccccc}
\hline Tahun & $\begin{array}{c}\text { Produksi } \\
\text { Hasil } \\
\text { Tangkapan } \\
\text { (Ton) }\end{array}$ & $\begin{array}{c}\text { Upaya } \\
(\mathrm{f}) \\
\text { (trip) }\end{array}$ & $\begin{array}{c}\text { CPUE } \\
\text { (U) } \\
\text { (Ton/trip) }\end{array}$ & $\begin{array}{c}\text { F } \\
\text { YTB } \\
\text { (trip) }\end{array}$ & $\begin{array}{c}\text { Y JTB } \\
\text { (Ton) }\end{array}$ & $\begin{array}{c}\text { Tingkat } \\
\text { Pemanfaat- } \\
\text { an (TP) } \%\end{array}$ & $\begin{array}{c}\text { Tingkat } \\
\text { Peng- } \\
\text { upayaan } \\
\text { (Tpu) (\%) }\end{array}$ \\
\hline 2006 & 1330.80 & 155 & 8.586 & 195 & 1232.86 & 108 & 144 \\
2007 & 1250.00 & 135 & 9.259 & 195 & 1232.86 & 101 & 133 \\
2008 & 1325.60 & 145 & 9.142 & 195 & 1232.86 & 108 & 135 \\
2009 & 1311.60 & 160 & 8.198 & 195 & 1232.86 & 106 & 150 \\
2010 & 1429.60 & 180 & 7.942 & 195 & 1232.86 & 116 & 155 \\
2011 & 1501.10 & 180 & 8.339 & 195 & 1232.86 & 122 & 148 \\
2012 & 1520.50 & 220 & 6.911 & 195 & 1232.86 & 123 & 178 \\
2013 & 1538.60 & 226 & 6.808 & 195 & 1232.86 & 125 & 181 \\
\hline
\end{tabular}

Untuk potensi stok cadangan lestari kondisi stok saat ini (standing stock) ikan cakalang, maka dianalisis dengan menggunakan model yang dikembangkan oleh Walter \& Hilborn. Berdasarkan model Walter \& Hilborn cara ke-1, diperoleh hasil analisis regresi linear dengan nilai $b_{0}$ sebesar 3,2188, nilai $b_{1}$ sebesar $-0,2526$ dan nilai $b_{2}$ sebesar $-0,0068$ dengan nilai $\mathrm{R}^{2}$ sebesar 0,51 (variasi CpUE dapat dijelaskan oleh variasi upaya penangkapan sebesar 51 persen). Selanjutnya didapatkan nilai $\mathrm{r}$ sebagai laju pertumbuhan alami stok biomass (konstan) sebesar -3,2188, nilai q (koefisien cathability) sebesar $-0,0068$ dan nilai $\mathrm{k}$ sebagai daya dukung maksimum lingkungan alami perairan (carrying capacity) sebesar 1871,446. Dengan menggunakan parameter r,q dan $\mathrm{k}$ maka pada kondisi stok saat ini (Standing Stock) diperoleh potensi stok cadangan lestari $\left(B_{e}\right)$ ikan cakalang di kabupaten luwu Sulawesi Selatan sebesar 935,72 ton/tahun.

Berdasarkan analisis model Walter dan Hilborn cara ke-2, diperoleh hasil analisis regresi linear dengan nilai $b_{1}$ sebesar 1,25667, nilai $b_{2}$ sebesar 0,135 dan nilai $b_{3}$ sebesar $-0,00745$. Selanjutnya didapatkan nilai laju r (laju pertumbuhan alami stok biomass/konstan) sebesar 1,25667, nilai 
q (koefisien cathability) sebesar 0,00745 dan nilai $\mathrm{k}$ sebagai daya dukung maksimum lingkungan alami perairan (carring capacity) sebesar 1247,082 dengan menggunakan parameter r, q, dan $\mathrm{k}$ maka pada kondisi stok saat ini (standing stock) diperoleh potensi stok cadangan lestari $\left(\mathrm{B}_{\mathrm{e}}\right)$ ikan cakalang sebesar 623,541 ton/tahun.

Untuk mengurangi bias yang diakibatkan perolehan nilai parameter populasi $\mathrm{r}$ dan $\mathrm{q}$ yang negatif, maka disarankan untuk menggunakan model Walter dan Hilborn cara ke-2. Berdasarkan perhitungan model Walter dan Hilborn cara ke-2 maka penentuan potensi stok cadangan lestari $\left(\mathrm{B}_{\mathrm{e}}\right)$ kondisi stok saat ini ikan cakalang di kabupaten luwu Sulawesi selatan diperoleh nilai $B_{e}$ sebesar 623,541 ton/tahun.

Berdasarkan analisis status pemanfaatan sumberdaya ikan cakalang di kabupaten luwu Sulawesi selatan maka berdasarkan model schaefer pada tahun 2013 tergolong undereksploited, dengan potensi stok cadangan lestari $\left(B_{e}\right)$ kondisi stok saat ini sebesar 623,541 ton/tahun. Untuk kepentingan kehati-hatian pemanfaatan sumberdaya ikan cakalang, maka perlu adanya upaya pengelolaan sumberdaya ikan cakalang yang berkelanjutan. Allan dan Castillo (2007), menyatakan kegiatankegiatan yang terkait dengan upaya pengelolaan sumberdaya perikanan perairan harus berlandaskan pada ilmu pengetahuan holistic dan berkelanjutan. Nikijuluw (2001) dan Neala et al., (2009) menyarankan bahwa pemanfaatan sumberdaya sumberdaya perlu kehati-hatian agar tidak sampai terjadinya kondisi kelebihan penangkap (overfishing). Prinsip kehati-hatian secara umum merupakan amanat yang di dasarkan pada resolusi PBB No. 4/95 tahun 1995, Food and Agricaltural Organisation (FAO), tentang Code Of Conduct For Responsible Fisheries (CCRF) atau kode etik untuk perikanan bertanggung jawab tentang pengaturan aspek-aspek yang bertujuan agar kegiatan perikanan dapat berlangsung secara berkelanjutan (sustainable) yakni CCRF pada pasal 7 ayat 5, selanjutnya hal ini juga merupakan amanat dari undang-undang Republik Indonesia No. 31 tahun 2004 tentang perikanan dan undang-undang Republik Indonesia No. 45 tahun 2009 tentang perubahan atas undang-undang Republik Indonesia No. 31 tahun 2004 dan Peraturan Pemerintah No. 60 tahun 2007 tentang konservasi sumberdaya. 


\section{KESIMPULAN}

Tingkat MSY dan Upaya optimum dari ke-tiga model (schaefer, Fox, Walter \& Hilborn) berkisar antara 935,72 - 1602,244 ton dan upaya optimum 235 - 303 trip. Tingkat pemanfaatan ikan cakalang menunjukkan eksploitasi ikan ini masih tergolong rendah.

\section{SARAN}

Untuk penelitian selanjutnya perlu dilalakukan perhitungan MSY dan upaya optimum untuk seluruh Kawasan teluk Bone.

\section{UCAPAN TERIMA KASIH}

Ucapan terma kasih disampaikan kepada Lembaga Penelitian dan Pengembangan Sumberdaya (LP2S) UMI yang telah membiayai penelitian ini dan juga kepada kepala dan Staf Dinas Kelautan dan Perikanan Kabupaten Luwu yang telah membantu memberikan Data.

\section{DAFTAR PUSTAKA}

Allan, J.D., and M.M. Castillo, 2007. Stream Ecology, Structure and Function of Running Waters. Second Edition. Pub. Springer. Netherlands, P. 429 p

Bintoro, G. 2005. Pemanfaatan Berkelanjutan Sumberdaya Ikan Tembang (Sardinella fimbriata Valenciennes, 1847) di Selat
Madura Jawa Timur. Disertasi, IPB Bogor

Charles A. 2001. Sustainable Fisheries System. Saint's Marine University, Halifax, Nova Scotia, Canada.

Coppola G and S. Pascoe, 1996. A Surplus Production Model with a non-linear Catch-Effort Relationship.(Research Paper 105) Center for the Economics and Managemant of Aquatic Resources University of Portsmouth

Dinas Kelautan dan Perikanan (DKP) Kabupaten Luwu Sulawesi Selatan. Laporan Statistik Perikanan. Tahun 2006 - 2013.

Dahuri, R. 2010. Pengelolaan Sumberdaya Wilayah Pesisir dan Lautan secara Terpadu. PT. Pradnya Paramita, Jakarta.

[FAO], 1995. Code of Conduct for Responsible Fisheries (CCRF). Rome. 40 p

Gulland, J.A., 1983. Fishing andStock of Fish at Iceland.Mui. 'Agric. Fish Food, Invest. (Ser.2) 23(4): $52-70$.

Neala, W.K, J.J. Hard, T.P. Quinn., 2009. Quantifying Six Decades of Fishery Selectiom for Size and Age at Maturity in Sockeye Salmon Evolutianary Application ISSN 17524571 Doi $10 \quad 1 \quad 1111 \mathrm{j} \quad 1752-45712009$ 00086 x. Journal Compilation 2009. Blacwell Publishing Ltd 2.

Nikijuluw, $\quad$ V.P.H., 2001. Pengembangan Perikanan 


\section{Tangkap Berwawasan \\ Lingkungan. Pustaka \\ Cidesindo, Jakarta}

Sparre, P and S.C. Venema, 1999 Introduksi Pengkajian Stok Ikan Tropis.Buku 1 Manual. (Terjemahan J. Widodo. I.G.S. Merta, S. Nurhakim, dan M. Badrudin). Pusat Penelitian dan Pengembangan Perikanan, Badan Penelitian dan Pengembangan Pertanian
(Kerjasama dengan Organisasi Pangan dan Pertanian Perserikatan Bangsa-bangsa). Jakarta. 438 hal.

Trevor D.D and K.B. Julia, 2012. Extinctions Risk and Overfishing Reconciling Conservation and Fisheries Perspectiives on The Status of Marine Fishes. Scientific Report Journal 2 561. DOI: 10. 11038.srep005611 